\title{
Perceptions of Students of Journalism on the Role of Media in the Albanian Society
}

\author{
Florenc Vavla \\ Prof. Asoc. Dr. Laureta Vavla \\ Aleksander Xhuvani University, Faculty of Human Sciences, Department of Journalism \\ Emailflorivavla@yahoo.com/lauretavavla@yahoo.com
}

\section{Doi:10.5901/ajis.2015.v4n3s1p622}

\begin{abstract}
This article aims to analyze the results of a study concerning students' perceptions of the role of media in the Albanian society, the way the messages given by the media are understood by the public and the effects media has on them. Eighty-two students of the branch of Journalism responded to both open and closed questions as well as to individual interviews. They strongly argued that the role of the media in the society is growing on a daily basis which calls for the need of the public to be educated on how to analyze and be critical of the information received by different media. However, the article concludes that professors and teachers are increasingly stimulating their students to think out of the box and to direct them towards not always accepting the status quo, per se, but rather think critically and with an open-mind.
\end{abstract}

Keywords: perceptions, media, media literacy, society

\section{Introduction and Research Background}

Researchers all around the world have commented and laid down their own theories in regards to the realistic nature of the television (Gitlin, 1980, 1983, Marc, 1989). Kuhn (1982: 25), for instance, has stated in regards to the American culture, that television has become a part of their daily life, it has been accepted in their routine and daily tasks. Therefore, the television can be considered as unique amongst the various media because its images have the capability of being unconsciously accepted by the viewers as images of reality and real life.

Undoubtedly, the media have become an integral part of our life and society. We are surrounded by various media whenever and wherever we are. Every individual knows this well, but what do students of journalism think about the role media plays in our society? What are their perceptions in regards to the news broadcasted on television or radio? What do they think about the audience: is the public able to distinguish between an opinion and a fact? Are the media consumers capable of analyzing and opposing untruthful news on the media?

The current study examines the perceptions of eighty-two journalist students of the second year of study at "Aleksander Xhuvani" University in Elbasan, Albania. The students' age range from 19-23 years old and this is the second year of their studies in the branch of Journalism in the university. Most of them do not have any experience as journalists apart from the mock radio programs organized by the department.

\section{Research Questions and Methodology}

The three research questions devised for this study were as follows:

- What is the role of media in the society?

- Is the public able to distinguish between truthful and false news on the media?

$\circ$ Is the news on the media a reflection of the reality we live in?

The questionnaire was divided into two sections. The first one served to collect data on the students' age and their educational and professional background and the second section aimed at collecting as much information as possible on the news given on the media and the way the public perceives them, the public's attitude towards unreal and biased news, the public's tendency to prejudice the news based on their personal views etc.

Students' perceptions on the role of media on the society

The main question to be raised is: what is the situation in Albania in regards to media consumption and analysis? There is no clear or confirmed picture regarding the use of media in Albania due to the lack of studies in the area, but 
there have been taken several small steps towards collecting information in this regards.

The results from our questionnaire have been focused on reporting the behaviors of youth towards media. A very interesting finding in our study shows that over half of the students reported that they never listened to the radio and the minority did this for only one hour a day at the most.

When asked about the television, $65 \%$ of the students declared that they spend 2 to 4 hours a day in front of the TV and $35 \%$ of them watch over 4 hours a day of TV programs. These figures show that TV remains the favorite media for this age-group. The questionnaire also confirmed the trend which is continuously growing of the use of internet. Over $4 / 5$ of the students interviewed in the study, answered that they use internet several times a day.

When asked about the role media plays in the Albanian society, $51 \%$ of the students answered that it plays an informative role, $30 \%$ believed that the media are mainly for entertainment and 19\% stated that the media are persuasive. It is obvious from the responses collected that media is seen mostly as informative. Whenever the society is in search of information, the media comes to their help.

Meanwhile, some of the comments given by the students were:

- In my family, TV plays a crucial role. Our family day starts by turning on the TV and listening to the latest news. I cannot imagine life without the television.

- Whenever I need an information I 'Google' it. Whenever I meet somebody new I 'facebook' him or her. I always turn towards various media for information I don't know. Up to now the use of media has proven to be efficient and real quick.

- Media are definitely widely used because they are both informative and entertaining! I mostly use the radio to listen to the latest songs and to inform myself on what is going on in the world and in my country. I also tend to use my mobile phone which now fulfills the functions of the radio, TV, internet, camera, video-recorder, etc.

- I consider Media to be highly persuasive, especially in Albania. People, in particular the elders spend a lot of time watching the news on television. The huge amount of time they spent in front of the TV, changes the way they perceive life in general and political life in particular. I see people who watch a particular TV channel or who buy a particular newspaper based on their political affiliation. These people are persuaded by the media and the politicians...

Evidently, the students who believed media to be primarily informative are a majority. Media is still seen as a communicative tool through which people and institutions can share and spread news among them. Being the first What is interesting to notice, is that media is not exclusive seen as informative but entertaining and persuasive altogether.

Television, radio and internet are now accessible and available in every household and life without media has quickly become unperceivable by young and old. In such a short time span, people have turned into mobile and internetfriendly and naturally this has led to an increase in the speed and accessibility of information and news. People are entertained through the use of media at such a degree that many believe that media (especially social media) is interfering in their personal and professional life. People now read whole volumes on their mobiles, get informed on the latest news and watch endless videos and listen to numerous songs. Media entertainment is abundant and infinite.

What is also extremely important to analyze is the fact that the students were aware of the fact that media plays a persuasive role and this power is increasingly being used and abused as a tool to manipulate the audience into believing and perceiving the news in such a way that suits one or the other rather than being merely objectively informative.

\section{Interviews Conducted with the Students}

In order to achieve a much thorough analysis of the perceptions of the media from the journalism students, the researchers conducted three individual interviews. Six questions were posed to three students: a male and two females. These three students were carefully chosen being representatives of their groups, not only based on their gender but also based on their educational background and social status. Below we will list and analyze the answers collected and transcripted by each and every student interviewed:

\subsection{Sidorela}

\subsubsection{The role of media in the society is always increasing}

That is absolutely very true. Media today even in the digital age has become part of our lives. Its role is growing rapidly, the TV channels are countless, and so are the various blogs on the Internet, which continuously feed us on everything 
happening and which inevitably influence our lives.

\subsubsection{The news on the media is a mirror of the reality in which we live}

I do not think this is true, despite the "marketing" from the side of the media. I believe that the media presents the news that it, or rather the government is interested to give to the public. The connection of the media with the political power is so strong that they are completely in tune with one another on how the reality is going to be represented. There is a lack of reality on the media and the main reason lies upon politics and politicians.

\subsubsection{Is the public able to distinguish between truthful and false news on the media?}

I think people do not have the necessary "tools" to distinguish it. Because of a general culture of trust towards the media, people often believe things that are not real. What is interesting is that some of us choose to blindly believe the press or other media, depending on the bias of the media. If there is a political adaptability between the media and the citizens, each story is believed by the people, despite that it does not meet the criteria of authenticity and trustfulness.

\subsubsection{The public knows how to spot a false portrayal in the media}

The public is unable to make this distinction, if it does not possess the tools and instruments for this. These instruments have to do precisely with media literacy and critical thinking of the media. These are very specific skills to be learned and acquired and are necessary to differentiate the real from the unreal in the media.

\subsubsection{The public is able to distinguish facts from opinions that appear in the media}

It is very difficult to achieve this from an unaccustomed and untrained public. Through manipulation, the media succeeds in 'selling' facts as opinions. Everything happens for a purpose, for a specific interest and almost always premeditated. I think that the Albanian society is disoriented about this aspect because the media are abusing more on this fact. The dividing line between fact and opinion has been completely lost and unfortunately, there are no signs of improvement of the situation.

\subsubsection{We are able to analyze and reject the false news in the media}

False news analysis and opposition is a prime mission that we should all have. Media literacy is a key element in this regard. Nowadays I am critical of any information I see on television or in different web pages. I believe that I am able to discern the fact that in many cases the media try to manipulate the public on many issues and different facts. What I see is that in many cases these are taken as true, as people do not generally analyze and know the media from the inside.

\subsection{Edvini}

\subsubsection{The role of the media in the Society is always increasing}

This is indisputable. Media already accompanies us everywhere, in every step of our lives. Without it we can not think of the future and I think that this role will increase even more.

\subsubsection{The news on the media is a mirror of the reality in Which We Live}

This does not always happen. News is a selection made by the media, to achieve a particular purpose. Media themselves choose the reality that they think is important or that people think is important.

\subsubsection{Is the public able to distinguish between truthful and false news on the media?}

Unfortunately I personally believed that I was able to discern this, but I have not been able to do this in every case. There are many elements in the construction of reality and multifaceted media, which at first glance appear to reflect reality, but 
they do not. We risk every day to confuse the real with the unreal, because this is what the media has offered us since its creation.

\subsubsection{The public knows how to spot a false portrayal in the media}

Even this is not as it seems. In many cases the media shows only sides that it decides to show in order to portray a character, for example, by not stopping into portraying other sides or by hiding one or more negative sides. And here we are at risk of being manipulated by the media, by not realizing it at all.

\subsubsection{The public is able to distinguish facts from opinions that appear in the media}

In general the public is not able to do so. I absolutely think I can do this only because I study journalism. I think I'm able to analyze and evaluate whether a given media message is a fact or whether it is an opinion of the journalist and the media themselves, to achieve a particular purpose. This is because the public cannot break down the language used by the media or even to distinguish the techniques to hide the fact from opinion.

\subsubsection{We are able to analyze and reject the false news in the media}

We are definitely able to do so. What we need is the knowledge required in this regard. If we all had knowledge on critical media and the way of thinking about it, then obviously we would have in our possession everything needed to correctly analyze the media. Obviously this would later bring opposition and the disclosure of the untruthful news.

\subsection{Sokoli}

\subsubsection{The role of the media in the Society is always increasing}

Media is part of our lives and it will be even stronger in the future. We should start to think about how we should behave and what to do to precede, the increasingly large role of the media in our lives.

\subsubsection{The news media are a mirror of the reality in which we live}

I think that the news media are a deliberate selection based on specific interests of a part of the reality of our lives and they are incomplete. The media in many cases select news for a particular purpose and they generally do not set the public interest as a priority, but they base the news on their interest or on power. The government and the media, are an inseparable binomial and their common purpose is the creation of a reality in their interest.

\subsubsection{People are able to distinguish reality from falsehood}

Many people are not able to do so. In many cases the media manages to create a story or event even when it does not exist. Most media are created and exist to benefit, so in this case they will do everything to serve their interest.

\subsubsection{The public knows how to spot a false portrayal in the media}

And here we are dealing with techniques that the media uses to communicate with the public. We unconsciously follow the media and we never think critically about it. If this happened, we would raise many questions. If we achieve this then we could understand that the reality may be far from what the media gives us.

\subsubsection{The public is able to distinguish facts from opinions that appear in the media}

I think that the public is unable to do so, particularly in Albania. This happens because of the fact that there is so great a confusion between these two things, and the media is so involved in the interests it has that it is impossible to discern what is fact and what is opinion. Since every data, or any event is placed in the mouth of a journalist in a media set then he has lost the garment of absolute truth and it is merely an interpretation, and in many cases just an opinion, unsupported by facts. 


\subsubsection{We are able to analyze and reject the false news in the media}

We may be able to analyze the news and highlight their falsehood. If we refer to the media literacy we would undoubtedly possess the set of skills necessary to do so. If the whole society would have these skills, then it would be very difficult for the media to use techniques to successfully achieve its "manipulation" of the public. Objection of untruthful news is another social contribution that is attributable to be made by those who are capable and who have the necessary knowledge, so as not to allow the public opinion to fall prey to fraud.

\section{Analysis of the Questionnaire and Conclusions}

If we look and analyze the answers given by the students we will easily notice their awareness about the role of media in the society and the impact that it has. This phenomenon happens mainly due to the fact that journalism students are closer to the media and they better understand how the media functions. They also know and understand the methods and elements that the media uses to "manipulate" and drive people into believing falsehoods.

Based on the analysis of the responses collected by the questionnaires it was easily evidenced that the students were aware of the fact that the spread of technology and internet access has led to an increase in the impact of the media. They believed that the dominance of media in the Albanian society is highly evident.

On the other hand, the three students who were interviewed agreed on the fact that the relationship of the media with the government is very close and thus the service the media offers to various political powers is quite large. It is observed by analyzing the responses of the students that they believe that the majority of the news which are sold as facts in the media, for the students are merely opinions.

In their responses the students were aware of the fact that the media are selective in the type of information they transmit and in what they decide to broadcast. Although none of the students mentions it, they support the theory of "setting the Agenda", a theory which basically can be translated by the fact that the media may not be able to control what an individual thinks, but the media can check what the public should consider to think of. The students also noted the impossibility of the general public to understand and respond to the media. They estimated that media literacy is the right the key to understanding the media and to stop its negative impact on the society.

\section{References}

Gitlin, T. (1980). The Whole World Is Watching: Mass Media in the Making and Unmaking of the New Left. Berkeley: University of California Press.

Gitlin, T. (1983). Inside Prime Time. New York: Pantheon.Goldberg, M. R., \& Gom,

Kuhn, A. (1982). Women's Picture. London: Routledge \& Kegan Paul.

Marc, D. (1989). Comic Visions: Television Comedy and American Culture. Winchester, MA: Unwin-Hyman. 